\title{
PROFILE OF CARDIOVASCULAR RISK FACTORS AND MORTALITY IN PATIENTS WITH SYMPTOMATIC PERIPHERAL ARTERIAL DISEASE
}

\author{
Silméia Garcia Zanati, ${ }^{\mathrm{I}}$ Guilherme Grisi Mouraria, ${ }^{\mathrm{I}}$ Luiz Shigero Matsubara, ${ }^{\mathrm{I}}$ \\ Mariângela Giannini, ${ }^{I I}$ Beatriz B Matsubara ${ }^{\mathrm{I}}$ \\ doi: $10.1590 / \mathbf{S 1 8 0 7 - 5 9 3 2 2 0 0 9 0 0 0 4 0 0 0 1 0}$
}

Zanati SG, Mouraria GG, Matsubara LS, Giannini M, Matsubara BB. Profile of cardiovascular risk factors and mortality in patients with symptomatic peripheral arterial disease. Clinics. 2009;64(4);323-6.

INTRODUCTION: The present study examines cardiovascular risk factor profiles and 24-month mortality in patients with symptomatic peripheral arterial disease.

DESIGN STUDY: Prospective observational study including 75 consecutive patients with PAD $(67 \pm 9.7$ years of age; 52 men and 23 women) hospitalized for planned peripheral vascular reconstruction. Doppler echocardiograms were performed before surgery in 54 cases. Univariate analyses were performed using Student's t-test or Fisher's exact test. Survival analysis at 24-month follow-up was performed using the Cox regression model and Kaplan-Meier method including age and chronic use of aspirin as covariates. Survival curves were compared using the log-rank test.

RESULTS: Hypertension and smoking were the most frequent risk factors (52 cases and 51 cases, respectively), followed by diabetes (32 cases). Undertreated dyslipidemia was found in 26 cases. Fasting glycine levels $(131 \pm 69.1 \mathrm{mg} / \mathrm{dl}) \mathrm{were}$ elevated in 29 cases. Myocardial hypertrophy was found in 18 out of 54 patients. Thirty-four patients had been treated with aspirin. Overall mortality over 24 months was $24 \%$ and was associated with age (HR: $0.064 ; \mathrm{CI}_{95}: 0.014-0.115 ; p=0.013$ ) and lack of use of aspirin, as no deaths occurred among those using this drug $(p<0.001)$. No association was found between cardiovascular death $(11$ cases $)$ and the other risk factors.

CONCLUSION: There is a high prevalence of uncontrolled (treated or untreated) cardiovascular risk factors in patients undergoing planned peripheral vascular reconstruction, and chronic use of aspirin is associated with reduced all-cause mortality in these patients.

KEYWORDS: Cardiovascular risk; Elderly; Aspirin; Vascular surgery; Smoking.

\section{INTRODUCTION}

Peripheral arterial disease (PAD) is a progressive condition that results in vessel stenosis and obstruction of arterial blood flow exclusive to the coronary and intracranial vessels. ${ }^{1}$ Advanced age, smoking and diabetes (DM) are risk factors associated with PAD. Other risk factors include hypertension $(\mathrm{AH})$, hyperlipidemia, gender (male), elevated

\footnotetext{
I Department of Internal Medicine, Botucatu Medical School - Botucatu/ SP, Brazil.

II Department of Surgery, Botucatu Medical School - Botucatu/SP, Brazil. Email: sgzanati@fmb.unesp.br

Tel.: 55143882.2969

Received for publication on September 01, 2008

Accepted for publication on December 16, 2008
}

glucose level, prior myocardial infarction (MI), heart failure, history of cerebrovascular events, and elevated plasma fibrinogen levels. ${ }^{2}$ As a manifestation of systemic atherosclerosis, PAD is a common condition associated with high morbidity and mortality. Left untreated, it increases the risk of heart attack, stroke, amputation, or death. ${ }^{3,4}$ Because atherosclerosis overlaps in multiple circulatory subsystems, a high incidence of coronary artery disease and cerebrovascular disease has been shown in PAD patients. ${ }^{5,6}$

It is well known that treatment of cardiovascular (CV) risk factors delays the progression of atherosclerosis, reduces cardiovascular events and improves survival and quality of life. ${ }^{7,8}$ Therefore, patients with PAD, as well as those with coronary artery disease (CAD), benefit from $\mathrm{CV}$ risk factor management. ${ }^{1,3,7}$ However, it seems that atherosclerosis risk 
factors are less tightly controlled in PAD patients when compared to CAD patients. ${ }^{6,9,10}$

To further address this issue, we examined patients with symptomatic PAD hospitalized for surgical vascular reconstruction. This study analyzed cardiovascular risk factor profiles and all-cause mortality over a 24 month period. We also evaluated cardiac alterations using conventional transthoracic Doppler-echocardiograms.

\section{METHODS}

\section{Study Design}

All procedures were approved by the research ethics committee of our Institution. All participants gave written informed consent.

From March 2002 to October 2003, seventy-five consecutive patients admitted for planned surgical repair of PAD were prospectively included in the study. The initial vascular diagnoses were lower extremity ischemia (65 cases) or carotid stenosis (10 cases).

Exclusion criteria were unstable hemodynamic conditions or request for an urgent surgical procedure. The primary endpoint was total mortality during the 24-month followup.

Patients were interviewed to assess smoking habits, AH, DM, dyslipidemia, and/or previous cerebrovascular events. A complete medical evaluation, including a standard 12-lead EKG, was performed for each patient by the same cardiologist (SGZ). Blood pressure control goals were $<140 / 90 \mathrm{mmHg}$, or $130 / 80 \mathrm{mmHg}$ if the patient presented with diabetes or chronic kidney disease. ${ }^{11}$

Blood cholesterol, triglycerides, fasting glucose, and creatinine levels were measured at hospital admission. Tests were performed by enzymatic reactions using kits from Johnson \& Johnson, or dry chemistry methodology with a Vitros 750 auto-analyzer. Considering that this population is at high risk for cardiovascular events, the following target limits were set: total cholesterol $<200 \mathrm{mg} / \mathrm{dl}$; LDLcholesterol $<100 \mathrm{mg} / \mathrm{dl}$, triglycerides $<150 \mathrm{mg} / \mathrm{dl}$, and fasting glycine levels $<126 \mathrm{mg} / \mathrm{dl}^{7}$

Standard transthoracic echocardiograms were performed in 54 cases within the first 24 hours of hospitalization, before surgery, following the American Society of Echocardiography Committee recommendations for chamber quantification. ${ }^{12}$ Left ventricular (LV) mass was calculated, and systolic function was evaluated by ejection fraction (EF) and percentage of LV diameter fractional shortening (\% FS). Diastolic function was evaluated by measuring transmitral flow peak velocities ( $\mathrm{E}$ and $\mathrm{A}, \mathrm{cm} / \mathrm{s}$ ), and $\mathrm{E} / \mathrm{A}$ ratio. Increased normalized wall thickness was taken as an index of ventricular concentric remodeling if the myocardial mass was within the reference range. ${ }^{12}$

All-cause mortality during the 24-month follow-up was the primary endpoint for this study. Statistical analyses were conducted using SYSTAT (version 10.2), and $p$-values of $<0.05$ (two-sided) were considered significant. Mean, standard deviation and proportion are presented. Univariate analyses were performed using Student's t-test or Fisher's exact test. Survival analysis in the 24-month follow-up was performed using the Cox regression model and Kaplan-Meier method, including age and chronic aspirin use as covariates. Survival curves were compared by using a log rank test.

\section{RESULTS}

Fifty-two men and 23 women $(p<0.001), 67 \pm 9.7$ years of age, were included in this study. Systolic and diastolic blood pressure were $129 \pm 18 \mathrm{mmHg}$ and $81 \pm 6 \mathrm{mmHg}$, respectively. Fasting glycine levels were $131 \pm 69 \mathrm{mg} / \mathrm{dl}$, total cholesterol $194 \pm 51 \mathrm{mg} / \mathrm{dl}$, LDL-cholesterol $123 \pm 46$ $\mathrm{mg} / \mathrm{dl}$, HDL-cholesterol $41 \pm 13 \mathrm{mg} / \mathrm{dl}$, triglycerides 150 $\pm 74 \mathrm{mg} / \mathrm{dl}$ and creatinine $1.16 \pm 0.40 \mathrm{mg} / \mathrm{dl}$. Arterial hypertension and current smoking were the most prevalent risk factors (52 cases and 51 cases, respectively), followed by diabetes (32 cases). Undertreated dyslipidemia was found in 52 cases. Fasting glycine levels $(131 \pm 69.1 \mathrm{mg} / \mathrm{dl})$ were elevated in 29 cases.

Fifteen patients presented a previous cardiovascular event and 12 had documented coronary artery disease. None underwent myocardial revascularization. The ankle-brachialindex was obtained in 61 cases, including all patients with lower extremity ischemia (mean \pm SD: $0.41 \pm 0.25$ ).

Doppler-echocardiograms revealed cardiac structural alterations in 32 of 54 patients. The main alterations included increased left atrium (LA) in 34 cases and myocardial hypertrophy or concentric remodeling in 23 cases. Diastolic dysfunction was found in 42 patients, but only one presented systolic dysfunction. Arterial blood pressure was similar in patients with or without left ventricular hypertrophy or concentric remodeling, and no association was found between these structural alterations and mortality.

Follow-up was performed at $19.6 \pm 8.15$ months. There were 18 deaths in 24 months from cardiovascular events (11 cases) or other causes ( 7 cases). The time of cardiovascularor non-cardiovascular-related death was similar $(5.8 \pm 3.2$ and $5.9 \pm 5.5$ months, respectively; $p=0.98$ ). In-hospital death occurred in two cases: one patient died from sepsis and the other from myocardial infarction. Univariate analyses (Table 1) showed that deaths occurred more often in older patients $(72 \pm 8.1$ vs. $66 \pm 9.7$ years old, $p=0.02)$ and in those with longer hospital stays $(27 \pm 16$ vs. $17 \pm$ 
10 days, $p=0.006)$. Age, gender, $\mathrm{AH}$, fasting glycine levels, dyslipidemia, creatinine and self-reported smoking were not associated with mortality. Overall mortality over 24 months was $24 \%$ and was correlated with age (HR: $0.064 ; \mathrm{CI}_{95}$ : $0.014-0.115 ; p=0.013$ ) as well as non-use of aspirin, as no deaths occurred among patients using this drug $(p<0.001$; Figure 1).

Table 1 - All-cause mortality and clinical variables

\begin{tabular}{lccc}
\hline & death & survival & P value \\
\hline gender (F/M) & $7 / 11$ & $16 / 41$ & 0,39 \\
Previous CV event (yes/no) & $2 / 16$ & $13 / 44$ & 0,28 \\
Diabetes mellitus (yes/no) & $7 / 11$ & $25 / 32$ & 0,71 \\
Age (years) & $72 \pm 8.1$ & $66 \pm 9.7$ & 0,02 \\
Fasting glycine (mg/dL) & $118 \pm 64$ & $136 \pm 70$ & 0,36 \\
LDL-C (mg/dL) & $117 \pm 42$ & $125 \pm 46$ & 0,56 \\
HDL-C (mg/dL) & $39 \pm 9$ & $41 \pm 14$ & 0,75 \\
TG (mg/dL) & $123 \pm 47$ & $158 \pm 78$ & 0,11 \\
Serum creatinine (mg/dL) & $1.25 \pm 0.50$ & $1.13 \pm 0.35$ & 0,35 \\
Use of aspirin (yes/no) & $0 / 18$ & $33 / 24$ & $<0.001$ \\
\hline
\end{tabular}

Student's $t$ test or Fisher exact test

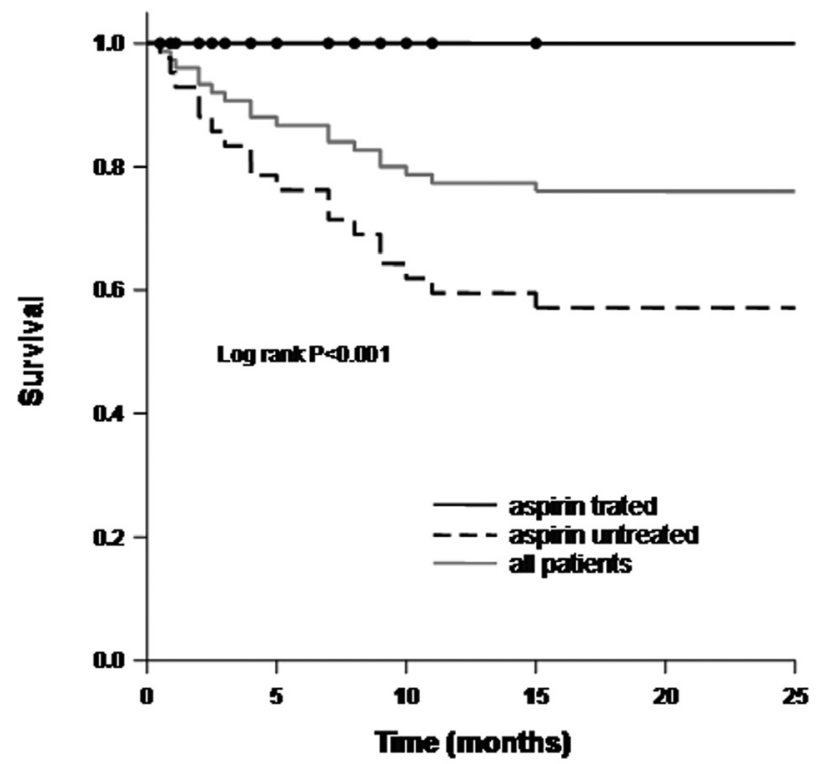

Figure 1 - Kaplan-Meier survival curves for participants under aspirin treatment (solid line) versus subjects without aspirin (dashed line). Survival curve in the 24-month follow-up for all 75 patients with severe peripheral arterial disease is displayed by gray line

\section{DISCUSSION}

The present study shows that despite a poor outcome, patients with PAD are undertreated for modifiable CV risk factors. This suggests that more appropriate management, including strategies to reduce this risk, should be provided. For instance, the majority of patients previously diagnosed with DM presented fasting glycine levels $>110 \mathrm{mg} / \mathrm{dl}$. This lack of proper risk factor control was even more remarkable for LDL-cholesterol. These data are in agreement with previous reports describing the high prevalence of untreated risk factors related to PAD in asymptomatic, non-diagnosed patients or in patients with known conditions. ${ }^{5,9,10}$

Although the mean blood pressure was not remarkably high, $21.3 \%$ of patients presented values above the optimal upper limit established for secondary prevention. ${ }^{11}$ However, it must be taken into account that these values only correspond to measurements obtained during the initial clinical evaluation; this could be misleading for conclusions about $\mathrm{AH}$ control in these patients.

Smoking cessation is the single most important factor associated with the outcome of patients with intermittent claudication. ${ }^{13}$ However, a report from the American Lung Association revealed that only $34 \%$ of smokers attempt to quit per year, and only $2.5 \%$ of those who try to stop actually succeed $^{14}$. In the present study $53.3 \%$ of the patients were current smokers, although all were referred to programs for smoking cessation.

Twenty-five percent of patients examined by echocardiography presented LV myocardial hypertrophy. Notably, these patients showed similar SBP and DBP when compared to those without hypertrophy. This suggests that treatment of $\mathrm{AH}$ is not the only requirement for reversing myocardial remodeling, as has been previously reported..$^{15}$ It is also possible that in this population, altered LV mass was related to causes other than hypertension, including comorbidities such as diabetes and smoking. ${ }^{16,17}$ This alteration was associated with enlarged cardiac left chambers and decreased left ventricular EF.

It is well known that ventricular remodeling causes myocardial relaxation impairment and diastolic dysfunction. In turn, diastolic dysfunction promotes increased pressure in the LA, which is typically the first cardiac chamber to dilate in this condition. In the present study, it is reasonable to assume that LA enlargement was caused by ventricular diastolic dysfunction. However, it is important to note that aging is also associated with reduced myocardial relaxation, decreased ventricular compliance, and LA enlargement.

A challenge in analyzing these data is how to differentiate age-related physiological dysfunction from that associated with diastolic heart failure. The latter condition presumes clinically detectable heart failure with preserved systolic function and impaired ventricular filling. ${ }^{18}$ None of our patients presented signs or symptoms of heart failure at rest. However, many were physically impaired due to 
intermittent claudication, preventing the clinical evaluation of exertion tolerance. Our findings suggest that Dopplerechocardiograms should be considered as an additional exam for all individuals with severe PAD, even in the absence of reported dyspnea.

The high mortality over the 24-month follow-up in the present study is in agreement with other evaluations of patients with severe PAD. ${ }^{1}$ Eleven patients died from MI or cerebrovascular ischemia, suggesting that atherosclerotic arterial disease was present in more than one arterial segment. A previous study including one thousand PAD patients identified a $25 \%$ prevalence of CAD by routine coronary angiography performed before elective peripheral vascular surgery. ${ }^{19}$ Peripheral arterial disease was in an advanced stage in all patients included in the present study, which would explain the high frequency of cardiovascular risk factors. This is an important observation, since these severely ill patients had neglected treatment for secondary prevention. It is remarkable that no patients died among those who had been chronically treated with aspirin. The beneficial effect of this drug is well-known for secondary prevention of both cerebrovascular and cardiovascular events.

In conclusion, there is a high prevalence of uncontrolled (treated or untreated) cardiovascular risk factors in patients undergoing planned peripheral vascular reconstruction. However, chronic use of aspirin was associated with reduced all-cause mortality in these patients.

\section{Study limitations}

The present study included a small population with PAD from a single Brazilian center. This limitation may explain the failure to detect any association between previous cerebrovascular events or myocardial hypertrophy and mortality. These associations are well documented in the literature. On the other hand, we were able to show that this high-risk population has been undertreated for cardiovascular risk factor and that there is an important association between death and the lack of use of aspirin.

\section{ACKNOWLEDGMENTS}

This study was supported by CNPq - Conselho Nacional de Desenvolvimento Científico e Tecnológico, Brasil and FAPESP - Fundação para o Amparo à Pesquisa do Estado de São Paulo.

\section{REFERENCES}

1. Ouriel K. Peripheral artery disease. Lancet 2001;358:1257-64 .

2. Belch JJF, Topol EJ, Agnelli G, Bertrand M, Califf RM, Clement $\mathrm{DL}$, et al. Critical issues in peripheral arterial disease detection and management. A call for action. Arch Intern Med. 2003;163:884-92.

3. Murabito JM, D' Agostinho RB, Silbershartz H, Wilson WJ. Intermitent claudication: a risk profile from the Framingham Heart Study. Circulation. 1997 Jul 1;96(1):44-9.

4. Strong JP. Atherosclerosis lesions. Natural history, risk factors and topography. Arch Pathol Lab Med. 1992;116:1268-75 .

5. Janes SEJ, West J, Hopkinson BR, Walsh JT. Pharmacological secondary prevention in people with peripheral arterial disease compared to those with coronary artery disease: a missed opportunity. Br J Cardiol. 2008; $15: 48-50$.

6. Hirsch AT, Halverson SL, Jacobson DT, Hotvedt PS, Lunzer MM, Krook $\mathrm{S}$, et al. The Minnesota regional peripheral arterial disease screening program: toward a definition of community standards of care. Vasc Med. 2001;6:87-96.

7. Faxon DP, Creage MA, Smith SC, Pasternak RCJ, Olin JW, Bettmann MA, et al. Atherosclerotic Vascular Disease Conference. Executive Summary: Atherosclerotic Vascular Disease Conference Proceeding for Healthcare Professionals From a Special Writing Group of the American Heart Association. Circulation. 2004;109:2595-604.

8. Grundy SM, Benjamin IJ, Burke GL, Chait A, Eckel RH, Howard BV, et al. Diabetes and Cardiovascular Disease: a Statement for Healthcare Professionals from the American Heart Association. Circulation.1999; 100:1134-46.

9. Rehring TF, Sandhoff BG, Stolcpart RS, Merenich JA, Hollis HW Jr. Atherosclerotic risk factor control in patients with peripheral arterial disease. J Vasc Surg. 2005;41:816-22.

10. Mukherjee D, Lingman P, Chetcuti S, Grossman PM, Luciano AE, Eagle KA, et al. Missed opportunities to treat atherosclerosis in patients undergoing peripheral vascular interventions: insights from the University of Michigan Peripheral Vascular Disease Quality
Improvement Initiative (PVD-QI2). Circulation. 2002;106:1909-12. 11. Smith SC Jr, Allen J, Blair SN. J Am Coll Cardiol. 2006;47:2130-4.

12. Lang RM, Bierig M, Devereux RB, Flachskampf FA, Foster E, Pellikka PA, et al. Recommendations for chamber quantification: a report from the American Society of Echocardiography's Guidelines and Standards Committee and the Chamber Quantification Writing Group, developed in conjunction with the European Association of Echocardiography, a branch of the European Society of Cardiology. J Am Soc Echocardiogr. 2005; 18:1440-63.

13. Faulkner KW, House AK, Castleden WM. The effect of cessation of smoking on the accumulative survival rates of patients with symptomatic peripheral vascular disease. Med J Aust. 1983;1:217-9.

14. American Lung Association. Trends in tobacco use. New York, NY: American Lung Association, Epidemiology and Statistics Unit; 2001.

15. Wachtel Kl, Rokkedal J, Bella JN, Aalto T, Dahlöf B, Smith G, et al. Effect of electrocardiographic left ventricular hypertrophy on left ventricular systolic function in systemic hypertension (the LIFE Study). Am J Cardiol. 2001;87:54-60.

16. Stiefel P, Miranda ML, Rodriguez-Puras MJ, García-Morillo S, Carneado $\mathrm{J}$, Pamies E, et al. Glucose effectiveness is strongly related to left ventricular mass in subjects with stage I hypertension or high-normal blood pressure. Am J Hypertension. 2004;17:146-53.

17. Felicio JS, Pacheco JT, Ferreira SR, Plavnik F, Moisés VA, Kohlmann OJ, et al. Hyperglycemia and nocturnal systolic blood pressure are associated with left ventricular hypertrophy and diastolic dysfunction in hypertensive diabetic patients. Cardiovasc Diabetol. 2006;5:19 .

18. Kitzman DW, Gardin JM, Gottdiener JS, Arnold A, Boineau R, Aurigemma G, et al. Importance of Heart Failure with Preserved Systolic Function in patients after 65 years of age. Am J Cardiol. 2001;87:413-9.

19. Hertzer NR, Beven EG, Young JR, O'Hara PJ, Ruschhaupt WF 3rd, Graor RA,et al. Coronary artery disease in peripheral vascular patients: a classification of 1000 coronary angiograms and results of surgical management. Ann Surg. 1984;199(2):223-33. 